\title{
Pharmacokinetics of a 5-fluorouracil liposomal delivery system
}

\author{
STEVEN T SIMMONS,' 2 MARK B SHERWOOD,' DAN A NICHOLS,' \\ ROBERT B PENNE,' THEODORE SERY,' AND GEORGE L SPAETH
}

From the 'William and Anna Goldberg Glaucoma Service of the Wills Eye Hospital, Department of Ophthalmology of Thomas Jefferson University, and ${ }^{2}$ Department of Ophthalmology, Albany Medical College, New York, USA

SUMmARY A liposomal delivery system was developed in an attempt to prolong ocular levels of 5-fluorouracil for glaucoma filtering surgery. The pharmacokinetics of the 5-fluorouracil liposomal delivery system were studied in normal pigmented rabbits with 5-fluorouracil labelled with carbon$14(\mathrm{C}-14) .{ }^{14} \mathrm{C} 5$-fluorouracil was incorporated into the liposomes at a concentration of $10 \mathrm{~g} / \mathrm{l}$ and injected subconjunctivally in doses of 5 and $10 \mathrm{mg}$. Concentrations of 5-fluorouracil were assayed at 10 time intervals from 0.5 to 96 hours in cornea, sclera, and conjunctiva and at six time intervals from 0.5 to 12 hours in aqueous. Two peak concentrations were noted at approximately one and eight hours, with measurable levels present at 96 hours. This study demonstrates the ability of this liposomal delivery system to prolong levels of 5-fluorouracial in normal pigmented rabbits.

5-Fluorouracil, a synthetic pyrimidine, has been shown to decrease fibroblast proliferation in vitro and has been used clinically to treat proliferative vitreoretinopathy ${ }^{2}$ and prevent the closure of conjunctival filtering blebs. ${ }^{3+}$ In preliminary studies 5-fluorouracil improved the final surgical outcome. Though various subconjunctival and intravitreal doses of 5-fluorouracil have been used, all have required frequent repetitive injections because of the short half-life of ocular 5-fluorouracil. These injections cause discomfort and inconvenience to the patient and carry the risk of haemorrhage, infection, conjunctival scarring, ocular perforation, and additional postoperative inflammation. The complications from these treatments include corneal and conjunctival epithelial toxicity. ${ }^{23}$ This epithelial toxicity has caused treatment regimens to be altered or discontinued. ${ }^{3}$ The peak concentrations of 5fluorouracil obtained have been implicated as the cause of this toxicity. ${ }^{5}$ Clinical success could be improved if the ocular half-life was increased and the peak concentration was decreased.

Microspheres in a variety of forms have been used successfully to prolong drug half-lives and diminish toxic side effects. ${ }^{6}$ 5-Fluorouracil was incorporated

Correspondence to Steven T Simmons, MD, Department of Ophthalmology, Albany Medical College, Albany, New York 12208 , USA. into a liposomal matrix, and the ocular pharmacokinetics of a single subconjunctival injection investigated in normal pigmented rabbits.

\section{Materials and methods}

Carbon-14 labelled 5-fluorouracil ( $1050 \mathrm{nCi} / \mathrm{mg})$ was incorporated into stabilised anionic liposomes at a concentration of $10 \mathrm{~g} / \mathrm{l}$. By liquid chromatography and distillate analysis $70 \%$ of the 5-fluorouracil was found to be incorporated with the liposomes and remained stable for longer than 168 hours. The liposomes consisted mainly of hydrogenated lipid phosphatides derived from egg. The phospholipids were composed of phosphatidylcholine $(75 \%)$ and phosophatidylethanolamine $(20 \%)$ with the primary fatty acids being stearate and palmitate. This system was found to be multilaminar by electron microscopy.

Dutch Belt pigmented rabbits $(1.5-2.5 \mathrm{~kg})$ were anaesthetised with a $0.7 \mathrm{ml}$ intramuscular injection of ketamine $(100 \mathrm{~g} / \mathrm{l})$ and acepromazine $(1 \mathrm{~g} / \mathrm{l})$. The liposomal 5-fluorouracil was injected under the inferior bulbar conjunctiva with a 27 gauge needle. $5 \mathrm{mg}(0.5 \mathrm{ml})$ and $10 \mathrm{mg}(1.0 \mathrm{ml})$ of liposomal 5 -fluorouracil were injected in the right and left eyes respectively. A conjunctival bleb was noted after each injection. The concentration of 5-fluorouracil 
Table 1 Concentration of 5 -fluorouracil following a $5 \mathrm{mg}$ injection of liposomal 5 -fluorouracil $(\mu \mathrm{g} / \mathrm{g}$ )

\begin{tabular}{|c|c|c|c|c|c|c|c|c|c|c|}
\hline & \multicolumn{10}{|c|}{ Time in hours } \\
\hline & $0 \cdot 5$ & 1 & 2 & 4 & 8 & 12 & 24 & 48 & 72 & 96 \\
\hline Sclera & 3393 & 2052 & 259 & 430 & $86 \cdot 2$ & $35 \cdot 0$ & $32 \cdot 6$ & $9 \cdot 7$ & $2 \cdot 5$ & 0.9 \\
\hline Conjunctiva $180^{\circ}$ from inj. & 112 & 109 & $24 \cdot 1$ & $8 \cdot 7$ & $16 \cdot 7$ & $5 \cdot 5$ & 0.9 & $2 \cdot 1$ & 0.7 & $0 \cdot 3$ \\
\hline Conjunctiva $0^{\circ}$ from inj. & 15475 & 5453 & 1132 & 340 & 1401 & 191 & 143 & $63 \cdot 0$ & $62 \cdot 6$ & $32 \cdot 0$ \\
\hline Whole cornea & 107 & 108 & $79 \cdot 6$ & $46 \cdot 5$ & 114 & $15 \cdot 0$ & $7 \cdot 7$ & $7 \cdot 0$ & $2 \cdot 0$ & $0 \cdot 3$ \\
\hline Central cornea & 125 & $18 \cdot 8$ & $5 \cdot 2$ & $14 \cdot 4$ & $23 \cdot 2$ & $9 \cdot 9$ & $3 \cdot 5$ & $4 \cdot 2$ & NA & NA \\
\hline Aqueous & $4 \cdot 5$ & $6 \cdot 2$ & 4.4 & $2 \cdot 5$ & $4 \cdot 3$ & $0 \cdot 2$ & NA & NA & NA & NA \\
\hline
\end{tabular}

Table 2 Concentration of 5-fluorouracil following a 10 mg injection of liposomal 5-fluorouracil $(\mu \mathrm{g} / \mathrm{g})$

\begin{tabular}{|c|c|c|c|c|c|c|c|c|c|c|}
\hline & \multicolumn{10}{|c|}{ Time in hours } \\
\hline & 0.5 & 1 & 2 & 4 & 8 & 12 & 24 & 48 & 72 & 96 \\
\hline Sclera & 5838 & 577 & 275 & 450 & 104 & $38 \cdot 5$ & $13 \cdot 1$ & 9.4 & 1.7 & $3 \cdot 2$ \\
\hline Conjunctiva $180^{\circ}$ from inj. & 106 & $24 \cdot 8$ & $63 \cdot 4$ & $45 \cdot 1$ & $91 \cdot 5$ & 13.9 & $3 \cdot 7$ & $6 \cdot 0$ & $3 \cdot 0$ & $1 \cdot 2$ \\
\hline Conjunctiva $0^{\circ}$ from inj. & 41457 & 34816 & 28406 & 4071 & 4070 & 272 & 195 & $57 \cdot 0$ & $90 \cdot 0$ & $37 \cdot 0$ \\
\hline Whole cornea & 226 & 215 & 155 & $79 \cdot 3$ & 140 & $23 \cdot 6$ & $12 \cdot 5$ & $19 \cdot 1$ & 1.9 & 1.9 \\
\hline Central cornea & 156 & $50 \cdot 8$ & $12 \cdot 5$ & $9 \cdot 0$ & $53 \cdot 0$ & $13 \cdot 3$ & $0 \cdot 1$ & $2 \cdot 2$ & NA & NA \\
\hline Aqueous & $12 \cdot 0$ & $11 \cdot 5$ & $7 \cdot 7$ & $5 \cdot 2$ & $10 \cdot 5$ & $0 \cdot 3$ & NA & NA & NA & NA \\
\hline
\end{tabular}

was measured at 10 time intervals $(0 \cdot 5,1,2,4,8,12$, $24,48,72,96$ hours) for conjunctiva, sclera, and cornea and at six time intervals $(0 \cdot 5,1,2,4,6,12$ hours) for aqueous. Two rabbits were used at each time interval except at 72 and 96 hours, when only one rabbit was employed.

At the specified time interval each rabbit was reanaesthetised with a $0.7 \mathrm{ml}$ intramuscular injection of ketamine $(100 \mathrm{~g} / \mathrm{l})$ and acepromazine $(1 \mathrm{~g} / \mathrm{l})$. An aqueous sample of $0 \cdot 15 \mathrm{ml}$ was obtained from the anterior chamber through a $\mathbf{3 0}$ gauge needle. Two limbal conjunctival specimens were excised, one overlying and the other $180^{\circ}$ from the liposomal 5fluorouracil injection. Each rabbit was killed with a $3.0 \mathrm{ml}$ intracardiac injection of euthanasia solution (Beuthanasia). After immediate enucleation the eyes were rinsed of overlying blood with normal saline and the specimens obtained. The sclera underlying the injection site was excised with a No. 15 Bard Parker blade. Central corneal or whole corneal specimens were removed with corneoscleral scissors.

All specimens and five samples of carbon-14 labelled liopsomal 5-fluorouracil were placed in scintillation vials and weighed with an analytical balance. All solid tissue specimens were dried prior to weighing. $50 \mu \mathrm{l}$ of normal saline were added to each scintillation vial, allowance being made for rehydration of the tissue specimens. $1 \mathrm{ml}$ of tissue solubiliser (Protosol) was added to each vial. When digested the solutions were neutralised with acetic acid, and $10.0 \mathrm{ml}$ of scintillation fluid was added to each vial. The radioactivity of all the samples was recorded in a liquid scintillation counter. Ten control vials containing appropriate quantities of the reagents used were recorded to assess background radioactivity.

\section{Results}

The average concentration of 5-fluorouracil in the six ocular tissues studied after a $5 \mathrm{mg}$ injection of liposomal 5-fluorouracil are displayed in Table 1. At 1,8 , and 96 hours following injection the average concentration of 5-fluorouracil and its metabolites was $109,16 \cdot 7,0 \cdot 3 \mu \mathrm{g} / \mathrm{g}$ in superior conjunctiva; 108 , 114 , and $0.3 \mu \mathrm{g} / \mathrm{g}$ in cornea and $3392,86 \cdot 2,0.9 \mu \mathrm{g} / \mathrm{g}$ in sclera respectively. The peak aqueous concentration was $6 \cdot 2 \mu \mathrm{g} / \mathrm{g}$.

The average concentration of 5-fluorouracil in the samples studied following a $10 \mathrm{mg}$ injection are shown in Table 2 . At 1,8 , and 96 hours the average concentration of 5-fluourouracil and its metabolites was $106,91.5$, and $1.2 \mu \mathrm{g} / \mathrm{g}$ in superior conjunctiva; 215,140 , and $1.9 \mu \mathrm{g} / \mathrm{g}$ in cornea; and 577,104 , and $3.2 \mu \mathrm{g} / \mathrm{g}$ in sclera respectively. The peak aqueous concentration was $12 \cdot 0 \mu \mathrm{g} / \mathrm{g}$.

The average recorded background radioactivity was $14 \mathrm{cpm}$. This figure was subtracted from the scintillation recordings of each specimen. $0.1 \mu \mathrm{g}$ of 5 fluorouracil was equivalent to $112 \mathrm{cpm}$, eight times greater than the average background recording.

\section{Discussion}

Blumenkranz et al. demonstrated that rabbit conjunctival fibroblast proliferation can be inhibited by 


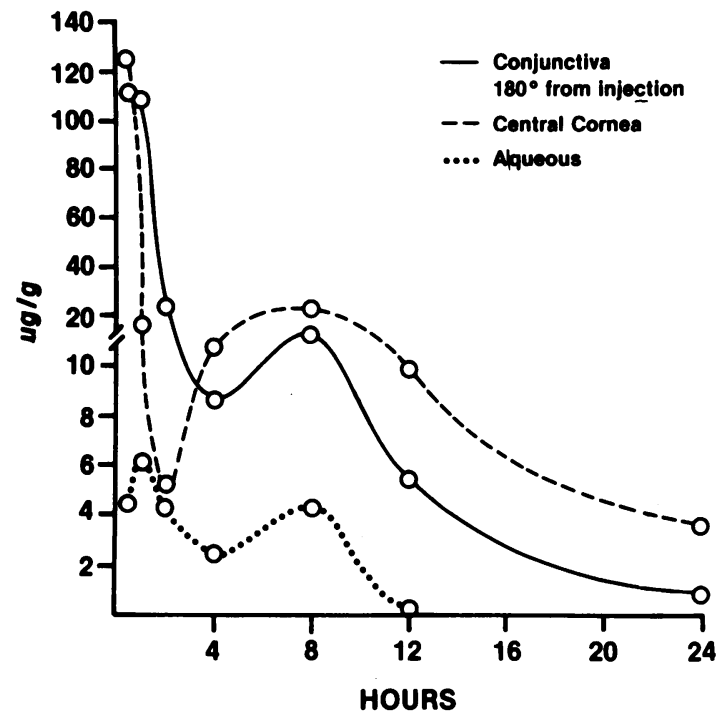

Fig. 1 Graphic representation of the 5-fluorouracil levels obtained in conjunctiva, cornea, and aqueous following a $5 \mathrm{mg}$ subconjunctival injection. The two peak concentrations seen in each tissue are consistent with a biphasic release of the 5-fluorouracil from the liposomal matrix.

$50 \%$ at a $0.2 \mu \mathrm{g} / \mathrm{l}$ concentration of 5 -fluorouracil in vitro.' In the present study this concentration was found in conjunctiva, cornea, and sclera 96 hours after a single injection, and in aqueous for more than 12 hours. Graphic representation (Fig. 1) demonstrates a biphasic release, with peak concentrations at 30 to 60 minutes and four to eight hours in all specimens. This is consistent with the release of separate fractions of incorporated and unincorporated 5-fluorouracil within the liposomal matrix. Electron microscopy of the liposomes following subconjunctival injection supports this hypothesis. Over the first eight hours the liposomes are shown to lose their configuration with the release of the bound drug.

The ideal delivery system would provide a high, prolonged concentration of 5-fluorouracil in the subconjunctival tissues overlying the filtering site, with low concentrations of 5-fluorouracil in the other ocular tissues. This would promote an antifibrotic

Table 3 Peak aqueous levels of 5-fluorouracil with various delivery methods

\begin{tabular}{lr}
\hline & $\mu g / g$ \\
\hline Subconjunctival liposomal 5-fluorouracil (10 mg) & $12 \cdot 0$ \\
Topical 5-fluorouracil (7.2 mg) & $199 \cdot 6$ \\
Subconjunctival 5-fluorouracil $(10 \cdot 5 \mathrm{mg})^{8}$ & 29.4 \\
\hline
\end{tabular}

Table 4 Peak ocular levels of 5-fluorouracil by various delivery methods

\begin{tabular}{|c|c|c|c|}
\hline & $\begin{array}{l}\text { Subconjunctival } \\
\text { liposomal } \\
5-\text { fluorouracil } \\
(10.0 \mathrm{mg})\end{array}$ & $\begin{array}{l}\text { Topical } \\
\text { 5-fluorouracil } \\
(7.2 \mathrm{mg})\end{array}$ & $\begin{array}{l}\text { Subconjunctival } \\
\text { 5-fluorouracil } \\
\text { (12.5 mg) }\end{array}$ \\
\hline Cornea & $226.0 \mu \mathrm{g} / \mathrm{g}$ & $502.9 \mu \mathrm{g} / \mathrm{g}$ & $457.6 \mu \mathrm{g} / \mathrm{g}$ \\
\hline Lens & $3 \cdot 1 \mu \mathrm{g} / \mathrm{g}$ & $6 \cdot 2 \mu \mathrm{g} / \mathrm{g}$ & NA \\
\hline Conjunctiva & $106 \cdot 0 \mu \mathrm{g} / \mathrm{g}$ & $589.8 \mu \mathrm{g} / \mathrm{g}$ & NA \\
\hline
\end{tabular}

NA = not available.

effect at the surgical site while minimising the toxic effects elsewhere in the eye. Comparison of peak levels obtained by this liposomal delivery system with those obtained in previous studies where 5fluorouracil was administered either by subconjunctival injection ${ }^{89}$ or by topical drops ${ }^{5}$ suggest that a lower peak concentration was obtained in aqueous (Table 3) and in all ocular tissues examined except for the conjunctiva overlying the liposomal injection site (Table 4).

On the other hand high levels of 5-fluorouracil in the sclera and conjunctiva located at the injection site were obtained throughout the 96 hours studied. The combination of lower peak concentrations of 5fluorouracil in the cornea and aqueous and high concentrations of 5-fluorouracil surrounding the subconjunctival injection site may have important clinical implications for the efficacy of this delivery system and for the placing of the liposomal matrix in relation to the filtering site.

In the analysis of the results of this study the levels of 5-fluorouracil found may have been elevated artificially as a result of simultaneous binocular injections. Rootman et al. have demonstrated aqueous levels of 5-fluorouracil in the contralateral eye following subconjunctival injection to be $3 \cdot 7 \%$ of those found in the injected eye at peak concentration. ${ }^{10}$ As a result the effect of binocular injections on the levels obtained is probably small and is insignifcant for future extrapolation in clinical studies.

This preliminary investigation demonstrates the possible applicability of liposomes to improving the delivery of 5-fluorouracil in glaucoma filtering surgery. The ability to prolong the scleral and conjunctival concentrations while reducing the peak ocular concentrations of 5-fluorouracil as shown in this study may prove beneficial to the success of surgery and the avoidance of secondary ocular toxicity. Future studies will be necessary to determine the effectiveness of the liposomal 5-fluorouracil to control fibroblast proliferation and inhibit bleb failure in comparison with standard therapy and 5fluorouracil alone. 
The authors have no commercial or proprietory interest in this liposomal delivery system and have received no financial support in performing this investigation.

The authors thank Dr Harun Takruri and Allergan Pharmaceuticals for their assistance in the development of this 5-fluorouracil liposomal delivery system. Dr Sherwood was partly supported by an International Glaucoma Association Grant.

\section{References}

1 Blumenkranz MS, Claflin A, Hajek AS. Selection of therapeutic agents for intraocular proliferative disease-cell culture evaluation. Arch Ophthalmol 1984; 102: 598-604.

2 Blumenkranz MS, Hernandez E, Ophir A, Norton EWD. 5Flourouracil: new applications in complicated retinal detachment for an established antimetabolite. Ophthalmology 1984; 91 : 122-30.

3 Heuer DK, Parrish RK, Gressel MG, Hodapp E, Palmberg PF, Anderson DR. 5-Fluorouracil and glaucoma filtering surgery: II. A pilot study. Ophthalmology 1984; 91: 384-93.

4 Gressel MG, Parrish RK, Folberg R. 5-Fluorouracil and glaucoma filtering surgery: I. An animal model. Ophthalmology 1984; 91: 378-83.

5 Fantes FE, Heuer DK, Parrish RK, Sossi N, Gressel MG. Topical fluorouracil: pharmacokinetics in normal rabbit eyes. Arch Ophthalmol 1985; 103: 953-5.

6 Davis SS, Illam L, McVie JG, Thomlinson F. Microspheres and drug therapy: pharmaceutical, immunological and medical aspects. Amsterdam: Elsevier, 1984.

7 Winter D, Simmons S, Jones M, Smith R. A histologic analysis of a 5-fluorouracil liposomal delivery system following subconjunctival injection in rabbits. Invest Ophthalmol Vis Sci 1987; 28 (suppl ARVO abstr): 271.

8 Fishman P, Peyman G, Hendricks R. Intravitreal and subconjunctival liposome-encapsulated 5-fluorouracil in a rabbit model. Invest Ophthalmol Vis Sci 1986; 27 (suppl ARVO abstr): 348.

9 Fantes FE, Parrish RK, Heuer DK. Subconjunctival fluorouracil: mechanism of ocular penetration. Invest Ophthalmol Vis Sci 1986; 27 (Suppl ARVO abstr): 322.

10 Rootman J, Tisdall J, Fundauskas G, Ostry A. Intraocular penetration of subconjunctivally administered ${ }^{1+} \mathrm{C}$-fluorouracil in rabbits. Arch Ophthalmol 1979; 97: 2375-8.

Accepted for publication 26 June 1987. 